\title{
PARADIGMAS EM ESTUDOS ORGANIZACIONAIS: UMA INTRODUÇÃO À SÉRIE
}

\author{
Miguel P. Caldas \\ Professor Associado da Loyola University New Orleans \\ E-mail: mpcaldas@oyno.edu
}

Com os dois artigos a seguir, a RAE inaugura a série "RAEClássicos: Textos Essenciais em Estudos Organizacionais". 0 objetivo da revista é proporcionar à comunidade acadêmica brasileira matéria-prima para reflexão e orientação em seu trabalho de pesquisa. 0 meu papel é apresentar e contextualizar a série, al ém de situar os dois artigos que compõem esta primeira parte da série no quadro da teoria das organizações no Brasil.

\section{PRODUÇÃO INTERNACIONAL E CONTEXTO LOCAL}

Nos últimos anos, a RAE trouxe aos seus leitores textos publicados em revistas acadêmicas internacionais de primeira linha. Como crítico constante da importação exagerada e acrítica de modelos estrangeiros também no campo da teoria administrativa, minha percepção sobre a inclusão desses textos em periódicos nacionais foi sempre ambivalente. Por um lado, creio ser o papel das publicações nacionais a veiculação de investigação científica que, antes de mais nada, derive da realidade local e a informe. Por outro lado, devemos considerar que nossos periódicos também têm outra missão, com a qual compartilho em intento e esforço, de inserir a produção científica nacional no cenário internacional. No que se refere à decisão de publicar textos estrangeiros já veiculados em outros países, esses dois objetivos são até certo ponto contraditórios: a abordagem mais local tenderia a reprovar a iniciativa, enquanto aquela que advoga inserção internacional talvez a apoiasse.

o que me motivou a participar da iniciativa desta série foi o seu caráter primordialmente didático e de formação de pesquisadores. Nos últimos anos, tive contato freqüente com as conseqüências negativas das deficiências de formação conceitual básica em teoria organizacional no Brasil. Como professor em cursos de mestrado e doutorado, não foram poucas as ocasiões em que me choquei ao ver alunos em situações quase absurdas, por pura falta de acesso a al gumas referências básicas. Muitos desses alunos estudavam temas fundamentados em teorias das quais nunca haviam lido os principais expoentes, a não ser por meio de apuds; muitas vezes, porque tais clássicos nunca haviam sido publicados em português. Outros alunos, diante de seus problemas de pesquisa, propunham metodologias quantitativas e hipotético-dedutivas, embora sua base teórica indicasse uma orientação indutiva e de caráter subjetivo. Outros ainda manifestavam "gostar de etnografia", e queriam usá-la para testar hipóteses de base objetivista e funcional! U ma boa parte queria juntar e citar em seu apoio (e não para sobrepor ou "metatriangular", como se discute nos textos a seguir) tudo o que havia lido na vida, de Karl Marx a Peter Drucker, passando eventualmente por Lair Ribeiro. Lembro-me de um al uno que experimentou severa crise ao descobrir que sua "idéia original" era, na verdade, o objeto básico da teoria neo-institucional, à época em voga há mais de 20 anos.

A lista de eventos desse tipo é longa na vida de qualquer docente brasileiro envolvido com programas de mestrado e doutorado. Ainda mais embaraçoso é perceber que tais problemas atingem também colegas em estágios avançados da carreira, o que pode ser constatado pela qualidade discutível e pela limitada contribuição dos artigos submetidos a eventos e periódicos brasileiros. De fato, a baixa qualidade e a limitada contribuição científica na produção brasileira em Administração tem sido tra- 
tada em muitos estudos, nas áreas de Estudos Organizacionais (M achado-da-Silva et al., 1990), Finanças (Leal et al., 2003), Marketing (Vieira, 2003), Tecnologia da Informação (Hoppen et al., 1998) e Recursos Humanos (Tonelli et al., 2003), assim como naAdministração como um todo (Quintella, 2003; Bertero et al., 1999; Caldas e Tinoco, 2004). De forma complementar, análises bibliométricas e de conteúdo têm mostrado que tais deficiências colocam em cheque a legitimidade de uma parcel a relevante de nossa produção (veja Tonelli et al., 2002; Vergara e Carvalho, 1995, 1996; Vergara e Pinto, 2000; Caldas e Tinoco, 2004).

De forma geral, minha opção tem sido por mitigar 0 problema mediante a sugestão de longas listas de leituras complementares, que compreendem em geral artigos e livros não disponíveis em português. Nunca deixei de me surpreender com o impacto positivo que tão singela incursão na literatura essencial do campo provocou nos alunos, bem como à sua trajetória intelectual posterior.

$\mathrm{Na}$ raiz da questão está um problema de acesso: há centenas de pesquisadores e estudantes que, devido à indisponibilidade de textos em português, acabam sem tomar contato com teorias e autores que poderiam ser cruciais à sua formação e ao seu trabalho de pesquisa. Nos últimos anos, testemunhei várias tentativas de publicar em português alguns desses textos essenciais ou "clássicos" (na falta de uma denominação mais adequada), que, entretanto, esbarraram na análise de viabilidade comercial das editoras.

É justamente nesse ponto que se situa este projeto, convergente com a missão da RAE, de "fomentar e disseminar a produção científica em Administração no Brasil". A revista tem enorme influência e, portanto, responsabilidade na difusão do pensamento administrativo desde sua formação (veja Bertero e Keinert, 1994). A nál ises bibliométricas ainda inéditas revelam ser a RAE o periódico nacional com maior impacto no campo, nas várias áreas da Administração. Milhares de docentes, estudantes, profissionais e pesquisadores em formação usam a RAE para atualizar-se e também para dar apoio em formação teórica básica. De certa forma, a RAE contrapõe a danosa influência nesse mesmo âmbito de conhecidos compêndios de teoria administrativa, caracterizados por atualidade, profundidade e qualidade duvidosas.

Assim, o projeto, que surgiu como uma simples proposta de introdução a um texto clássico, rapidamente evoluiu para a organização de uma série, que tem como objetivo a criação de um referencial básico de textos essenciais, nunca antes disponíveis em português. Desejamos partilhar esse trajeto e as respectivas apresentações dos textos com colegas que comungam os mesmos ideais.

Cabe observar que não há aqui nenhuma veneração aos textos e autores incluídos. Esta série tampouco deve ser vista como uma desconsideração em relação à produção local. Trata-se, na verdade, de uma coleção de textos representativos da melhor produção internacional, cuja divulgação em português deve ser vista como um incentivo à reflexão crítica e eventual incorporação. Desejamos incentivar a produção nacional "bem informada", contribuindo para sanar o problema defalta de acesso a pelo menos uma pequena parte daquilo que julgamos básico e que deveria ser conhecido.

\section{COMO SELECIONAR O ESSENCIAL}

Se a qualquer um de nós, acadêmicos brasileiros da área de Administração, fosse perguntado quais são os textos essenciais para quem desejar se aventurar no ensino e pesquisa em estudos organizacionais, a diversidade de respostas seria enorme. A pesar de sermos relativamente poucos, a "diáspora" que ocorreu no campo desde sua constituição no Brasil (veja Bertero, Caldas e Wood, 1999) multiplicou o número de "cultos", aos quais nos afiliamos, em palavra ou ação, como pesquisadores. No entanto, alguns textos apareceriam com maior freqüência, por constituírem passagem obrigatória na formação do acadêmico nacional, em disciplinas como Teoria Geral da Administração ou Teoria Organizacional, ou por serem clássicos inquestionáveis, como os principais trabaIhos de Herbert Simon e Max Weber, ou dos brasileiros Alberto Guerreiro Ramos, Maurício Tragtenberg e Fernando C. Prestes Motta.

Nesta série, trataremos especificamente de artigos acadêmicos ainda não disponíveis em português. Não focalizaremos textos que sejam localmente conhecidos, por sua publicação em livros ou artigos. Cabe notar que a inserção do primeiro texto da série, de Gareth Morgan, foi feita menos por sua conhecida abordagem metafórica (divulgada e conhecida no Brasil) do que por sua defesa da caracterização paradigmática que alicerça a teoria organizacional. Também não focalizaremos somente textos clássicos, no sentido mais restrito da palavra. Entre dois artigos que possam introduzir uma mesma teoria ou conceito essencial, escolheremos o mais recente, ou tentaremos incluir um texto complementar reflexivo que Ihe dê perspectiva, como é o caso do segundo artigo desta primeira edição da série.

Alguns textos virão de correntes teóricas que têm atin- 
gido popularidade no Brasil, como o neo-institucionalismo, mas cujos textos-base não estão ainda disponíveis em português. Outros serão incluídos para prover conceitos-chave, como os debates em torno de voluntarismo versus determinismo organizacional, ou a questão dos níveis de análise, cujas bases não foram divulgadas em nosso idioma. M esmo assim, devemos admitir que muitos artigos relevantes serão excluídos, seja pela indisponibilidade de obtenção de direitos autorais, seja pela limitação de espaço físico na revista.

\section{PARADIGMAS, METÁFORAS E METATRIANGULAÇÕES}

A discussão sobre os paradigmas em estudos organizacionais, que Gareth M organ toma por empréstimo de seu trabalho de 1979 com Gibson Burrell, é, em nosso entender, essencial ao pesquisador do campo. Com este artigo de 1980, que ora reproduzimos, Morgan - à época um doutorando galês saído de Lancaster, na Inglaterra, e começando a vida acadêmica na América do N orte - conseguiu veicular sua perspectiva pouco convencional sobre teoria organizacional na mais tradicional publicação do campo: a Administrative Science Quarterly.

0 artigo apresenta dois elementos. 0 primeiro éa exposição de seu model o de "paradigmas sociológicos", ou seja, uma base ontológica e epistemológica que, segundo Morgan e Burrell, fundamentariam as teorias organizacionais modernas. No livro publicado no ano anterior, e que Morgan procura sintetizar no artigo, Burrell e M organ (1979) sugeriam que o campo de teoria organizacional seria formado por uma série de posições epistemológicas e ontológicas de base, as quais formariam algumas posições metateóricas a priori no desenvolvimento científico em análise organizacional. Cada um desses quase-paradigmas paralel os coexistiria na área e influenciaria teorias que seriam aprisionadas por seus próprios pressupostos e desconheceriam ou ignorariam os demais "silos" representados por "campos concorrentes". Por sua vez, cada um desses campos de conhecimento iniciariam ciclos (ditos "paradigmáticos") semelhantes aos que Kuhn (1970) havia descrito a partir de seu conceito de "resolução de quebra-cabeças" (M cCourt, 1997).

De forma didática, Burrell e M organ (1979) apresentaram à academia de Administração norte-americana um modelo de categorização dos campos paradigmáticos. Os autores sobrepunham dois eixos: um representaria os pressupostos metateóricos sobre a natureza da ciência, opondo a ciência "objetivista" à ciência "subjeti- vista", enquanto o outro simbolizaria as premissas metateóricas sobre a natureza da sociedade, contrastando uma sociologia da "regulação" a uma sociologia da "mudança radical".

O conhecido diagrama que resulta da sobreposição desses dois eixos define 0 que os autores entendem ser os quatro principais paradigmas que fundamentariam ou que poderiam fundamentar - a análise organizacional. Seu argumento é que o desconhecimento dessa realidade paradigmática inconsciente e indiscutida, bem como a aceitação tácita quase hegemônica do paradigma funcionalista (no quadrante objetivista e regulacionista do diagrama), estariam aprisionando e limitando o desenvolvimento do campo, e seria sua missão "libertá-lo" e expandir seus limites. Ou seja, a intenção seria a de, em primeiro lugar, sugerir que o campo cresceria em reflexividade e riqueza se os distintos paradigmas pudessem se reconhecer e eventual mente dialogar no processo de desenvolvimento científico e, em segundo lugar, desvendar caminhos metateóricos pouco explorados e promissores, além do funcionalismo dominante, especialmente os referenciais críticos e interpretativos.

0 segundo elemento apresentado pelo texto de Morgan é sua conceituação da visão metáfora da teoria organizacional e da realidade organizacional, que foi divulgada no Brasil pela publicação, em 1996, do livro Imagens da organização (Editora Atlas). Em função da ampla divulgação deste segundo elemento, ele não será aqui comentado. Vale, entretanto, registrar que: (a) ambos os elementos originam-se do mesmo trabal ho de Morgan com Burrell, seu professor em Lancaster; (b) a discussão sobre metáforas que Morgan inicia neste artigo em 1980 é um esforço de refinamento e aprofundamento do criticado conceito de "analogia" utilizado no livro de 1979 (McCourt, 1997; Oswick, Keenoy e Grant, 2002); (c) 0 trabalho marca também um afastamento entre mestre e aluno - enquanto Morgan focaliza a análise metafórica, aprofundando e popularizando seu trabal ho com Burrell (Palmer e Dunford, 1996), este último segue um caminho de busca e exploração de rumos alternativos aos próprios quatro paradigmas, divulgando e patrocinando 0 movimento pós-modernista em análise organizacional (Burrell, 1996; Cooper e Burrell, 1994) e a corrente feminista em organizações (Burrell, 1984); e (d) o caminho que Morgan iniciou o guindou à condição de superstar na análise organizacional (especialmente fora dos EUA), levou-o cada vez mais a legitimar o conceito de metáforas organizacionais e, ao menos nos últimos 10 anos, conduziu-o a uma carreira de pal estrante e consultor internacional (para observar a vida e trajetória in- 
telectual de Morgan, veja, entre outros, www.schulich. yorku.ca e www.imaginiz.com).

De qualquer forma, o impacto do trabal ho de Burrell e Morgan no campo é inquestionável, em grande parte pelo artigo de 1980 e por sua seqüência (M organ, 1983). Nos últimos 25 anos, Burrell e Morgan tiverem um papel crucial: primeiro, na popularização e crescente aceitação de tradições teóricas críticas e interpretativas na teoria organizacional; e, segundo, na promoção de diálogos interparadigmáticos, dos quais o texto de Lewis e Grimes, também aqui traduzido, irá se ocupar extensivamente.

No Brasil, a popularização do conceito de paradigmas de Burrell e Morgan na década de 1980, bem como do trabalho de Morgan sobre metáforas durante os anos 1990, foram cruciais na popularização e legitimação de perspectivas críticas em organizações. Trabalhos hoje clássicos no Brasil (e.g. Machado-da-Silva et al., 1990) usaram os quatro paradigmas para analisar a produção científica, o que desde então foi reproduzido como protocolo de análise, quase sempre evidenciando a preocupante hegemonia do funcionalismo na teoria organizacional que se faz e se reproduz no Brasil, e promovendo a diversidade paradigmática na direção de outros referenciais. 0 uso de Burrell e M organ para a formação de mestres e doutores foi intensivo, especialmente entre meados da década de 1980 e meados da década de 1990, pelas mãos de professores tais como Fernando C. Prestes Motta, Carlos Osmar Bertero, M aria Tereza Fleury, Sylvia Vergara, Clóvis Machado-da-Silva, Roberto Fachin e Tânia Fischer, entre muitos outros.

Paradoxalmente, a partir de meados da década de 1990, talvez pela divulgação do livro Imagens da organização, 0 trabal ho de Burrell e M organ cai drasticamente de uso. Por exemplo, entre 1997 e 2002, dentre as quase 50 mil citações registradas em todos os trabal hos publicados nos Enanpads, apenas 14 são feitas ao livro de Burrell e Morgan, de 1979. No mesmo período, Morgan é citado quase 200 vezes (um terço delas na área de organizações), dois terços das quais são citações ao livro Imagens da organização. Ou seja, a redução do uso desse importante trabalho, que o livro de Morgan não substitui em nenhuma medida, faz de "Paradigmas sociológicos e análise organizacional" um dos textos mais influentes, porém menos efetivamente lidos, da teoria organizacional. Desejamos que a disponibilização deste artigo de M organ abra novamente caminho para a sua utilização no Brasil.

Por outro lado, o trabal ho de Burrell e Morgan também passou a ser criticado. De acordo com alguns críticos, o modelo de paradigmas simultâneos que Burrell e Morgan propuseram catalisou a proliferação de perspec- tivas concorrentes, ou ao menos sua popularização e aceitação no campo. Além disso, também gerou polarização e segregação. Assim, ao evidenciar diferenças elementares, Burrell e Morgan promoveram a segregação das perspectivas.

Muitos críticos (veja revisão, por exemplo, em McCourt, 1997; Oswick, Keenoy e Grant, 2002) apontaram a excessiva ortodoxia da chamada "incomensurabilidade paradigmática" e o banimento do diálogo e o crescimento interparadigmático com conseqüências negativas do trabal ho de Burrell e Morgan. Morgan respondeu a essa polêmica aprofundando a discussão de analogias e metáforas e advogando a maximização da reflexividade e da capacidade analítica que tal abordagem geraria, tanto para pesquisadores quanto para profissionais (M organ, 1996). Por sua vez, Burrell (1996) reagiu a M organ criticando a excessiva promiscuidade paradigmática e sugerindo que Morgan poderia estar dando a falsa impressão de que paradigmas e modelos metateóricos são intercambiáveis como produtos em prateleiras de supermercados. Outros teóricos argumentaram que a proliferação paradigmática promoveu a "anarquia" no campo, que deveria ater-se a um paradigma dominante, em geral aquele relacionado ao postulante (por exemplo, ver Donaldson, 1985) ou por ele escolhido (Pfeffer, 1997).

N esta primeira edição da série, sel ecionamos também o instigante texto de Lewis e Grimes, publicado em 1999 na prestigiosa Academy of Management Review, para exemplificar a corrente que defende o diálogo e co-desenvolvimento interparadigmático, e que procura desenvolver pesquisa e gerar conhecimento por meio da oposição sistemática e proposital de perspectivas opostas.

0 texto é bem construído e atualizado. Além disso, oferece recursos importantes ao pesquisador. Em primeiro lugar, o texto registra a produção dos pesquisadores "multiparadigmáticos" e "interparadigmáticos", incluindo vários tipos e formas de manifestação dessas abordagens. Acredito que, como eu, o leitor que já admirava ou aplicava abordagens interparadigmáticas irá achar curiosa e rel evadora a sua desconstrução na tipologia de aplicações levada a cabo pelos autores. Em segundo lugar, o trabalho tem grande mérito também pela prescrição estruturada da abordagem de pesquisa interparadigmática, denominada "metatriangulação", uma técnica que eles revisam e ampliam neste artigo. Em terceiro lugar, cabe registrar que o texto tem grande valor também para leitores não acadêmicos, ou leitores acadêmicos mais próximos da prática gerencial, pois traz um exemplo de aplicação da técnica de metatriangulação a um caso de tecnologia avançada de manufatura. Lewis e Grimes revê- 
em e ampliam significativamente o trabalho de Burrell e M organ 20 anos após a publicação do livro que popularizou a categorização paradigmática em estudos organizacionais.

Estimo que o leitor de RAE - seja para sua própria formação ou desenvolvimento, seja para o seu uso em pesquisa ou no ensino - verá grande utilidade nestas duas obras.

\section{REFERÊNCIAS BIBLIOGRÁFICAS}

BERTERO, C. O.; KEINERT, T. M. M. A evolução da análise organizacional no Brasil (1961-1993). Revista de Administração de Empresas, v. 34, n. 3, p. 81-90, 1994.

BERTERO, C. O.; CALDAS, M.; WOOD, T. Produção científica em administração de empresas: provocações, insinuações e contribuições para um debate local. Revista de Administração Contemporânea, v. 3, n. 1, p. 147$178,1999$.

BURRELL, G. Normal science, paradigms, metaphors, discourses and genealogies of analysis. In: CLEGG, S.; HARDY, C.; NORD, W. (Eds.). Handbook of Organization Studies. London: Sage, 1996.

BURRELL, G. Sex and organizational analysis. Organization Studies, v. 5, n. 2, p. 97-119, 1984.

BURRELL, G.; MORGAN, G. Sociological paradigms and organizational analysis. London: Heinemann Educational Books, 1979.

CALDAS, M. P.; TINOCO, T. Pesquisa em gestão de recursos humanos nos anos 1990: um estudo bibliométrico. Revista de Administração de Empresas, v. 44, n. 3, p. 100-114, 2004.

COOPER, R.; BURRELL, G. Modernism, postmodernism and organizational analysis: an introduction. Organization Studies, v. 9, n. 1, p. 91-112, 1988.

DONALDSON, L. In D efense of Organization Theory: A Reply to the Critics. Cambridge, UK: Cambridge University Press, 1985.

HOPPEN, N. et al. Sistemas de informação no Brasil: uma análise dos artigos científicos dos anos 90. In: ENCONTRO NACIONAL DA ASSOCIAÇÃO NACIONAL DOSPROGRAMASDE PÓS-GRADUAÇÃO EM ADMINISTRAÇÃO, 22., 1998. Foz do I guaçu. Anais. Foz do I guaçu: AN PAD, 1998.

KUHN, T. S. The Structure of Scientific Revolutions. Chicago: University of Chicago Press, 1962.

LEAL, R.; OLIVEIRA, J.; SOLURI, A. Perfil da pesquisa em finanças no Brasil. Revista de Administração de Empresas, v. 43, n. 1, p. 91-104, 2003.
MACHADO-DA-SILVA, Clóvis L., CUNHA, Vera C., AMBONI, Nério. Organizações: 0 estado da arte da produção acadêmica no Brasil. In: ENCONTRO ANUAL DA ASSOCIAÇÃO NACIONAL DOS PROGRAMAS DE PÓS-GRADUAÇÃO EM ADMINISTRAÇÃO, 14., 1990, Florianópolis. Anais. Florianópolis: ANPAD, 1990.

MCCOURT, W. Discussion note: using metaphors to understand and to change organizations: a critique of Gareth M organ's approach. O rganization Studies, v. 18, n. 3, p. 511-522, 1997.

MORGAN, G. Paradigms, metaphors, and puzzle solving in organization theory. Administrative Science Quarterly, v. 25, n. 4, p. 605-622, 1980.

MORGAN, G. More on metaphor: why we cannot control tropes in administrative science? Administrative Science Quarterly, v. 28, n. 4, p. 601613, 1983.

MORGAN, G. Imagens da organização. São Paulo: Atlas, 1996.

OSWICK, C.; KEEN OY, T.; GRANT, D. M etaphor and analogical reasoning in organization theory: beyond orthodoxy. Academy of M anagement Review, v. 27, n. 2, p. 294-303, 2002.

PALMER, I.; DUNFORD, R. Conflicting uses of metaphors: reconceptualizing their use in the filed of organizational change. Academy of M anagement Review, v. 21, n. 3, p. 691-717, 1996.

PFEFFER, J. Barriers to the advance of organizational science: paradigm development as a dependent variable. Academy of M anagement Review, $v$. 18, n. 4, p. 599-620, 1993.

QUINTELLA, R. Encontro nacional da Anpad x M eeting of AOM : lições, questionamentos e especulações. Revista de Administração de Empresas, v. 43, n. 3, p. 107-115. 2003.

TONELLI, M.; CALDAS, M.; LACOMBE, B; TINOCO, T. Produção acadêmica em recursos humanos no Brasil: 1991-2000. Revista de Administração de Empresas, v. 43, n. 1, p. 105-122, 2003.

VERGARA, S. C.; PINTO, M. C. S. Nacionalidade das referências teóricas em análise organizacional: um estudo das nacionalidades dos autores referenciados na literatura brasileira. In: ENCONTRO NACIONAL DE ESTUDOS ORGANIZACIONAIS, 24., 2000, Curitiba. Anais. Curitiba: ANPAD, 2000.

VERGARA, S. C.; CARVALHO JR., D. S. Nacionalidade dos autores referenciados na literatura brasileira sobre organizações. In: EN CONTRO ANUAL DA ASSO CIAÇÃO NACIONAL DOS PROGRAMASDE PÓS-GRADUAÇÃO EM ADMINISTRAÇÃO, 19., 1995, João Pessoa. Anais. João Pessoa: AN PAD, 1995.

VERGARA, S. C.; CARVALHO JR., D. S. Refletindo sobre as possíveis conseqüências da análise organizacional apoiada em referências estrangeiras. Revista de Administração Pública, v. 30, n. 6, 1996.

VIEIRA, F. G. Narciso sem espelho: a publicação brasileira de marketing. Revista de Administração de Empresas, v. 43, n. 1, p. 81-90, 2003. 